\title{
ARSENIC IN GROUNDWATER: ELEMENTS OF A NATIONAL STRATEGY FOR REDUCTION AND ERADICATION
}

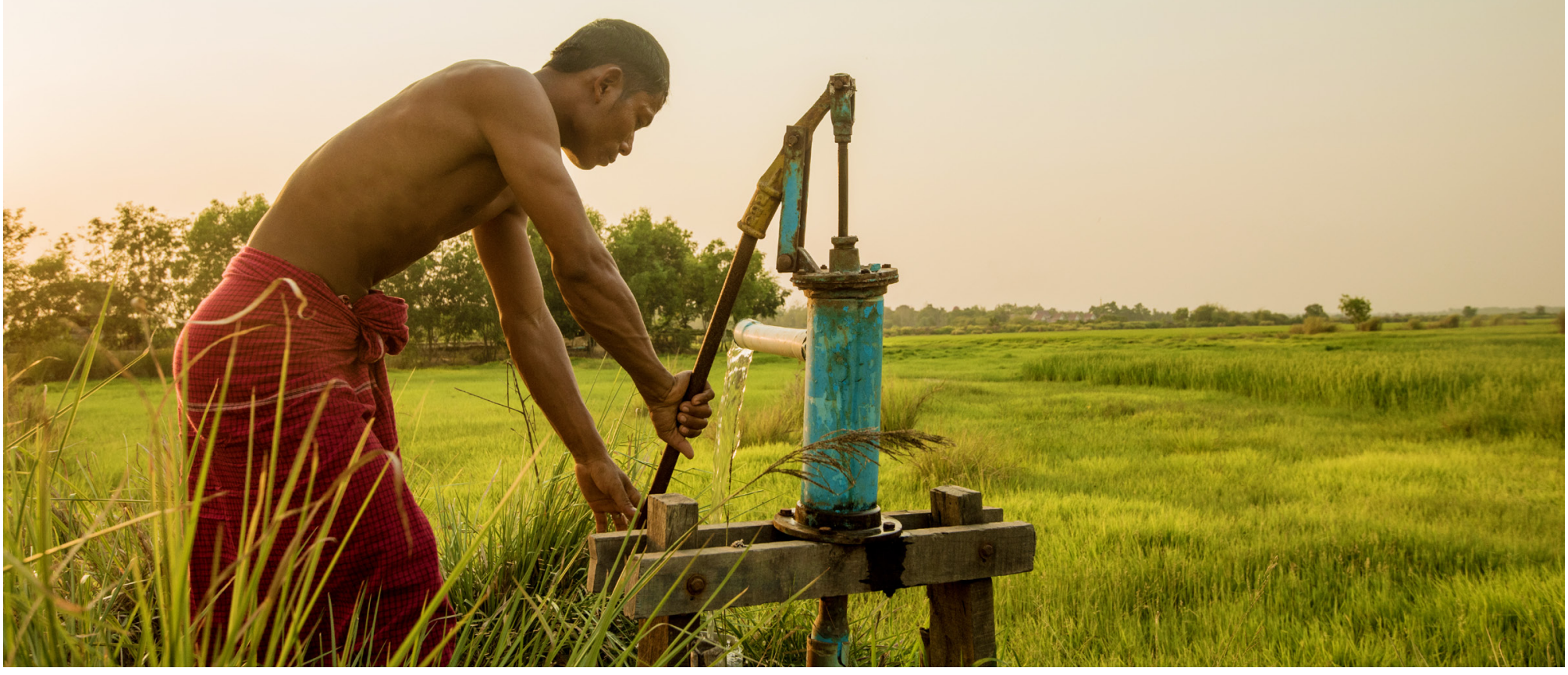

Arsenic contamination of groundwater is a serious public health crisis that currently affects an estimated 140 million people in roughly 50 countries. Despite decades of research and technical assistance efforts by governments, development agencies and international NGOs, arsenic poisoning of rural populations through groundwater persists across large parts of Asia, in Africa and South America.

This briefing looks at the reasons why the arsenic problem persists in many low-income countries and presents practical approaches to inform decision makers interested in creating a national plan to reduce and ultimately eradicate the problem. Applying the principles and solutions presented here, affected countries and their international partners can set realistic timelines for reduction and eradication of arsenic contamination of drinking water.

\section{Five aspects to address in the national plan}

Technologies that remove arsenic from contaminated water are well-known and in use across the affected countries. However, choosing the right technology is only a part of the solution. For decision makers in affected low-income countries, the answer lies in comprehensive national policies and strategies that address the technical, societal and practical aspects of their arsenic situation.

An effective policy plays out in action plans to reduce and eventually eradicate the problem. To achieve this, three groups need to work together: i) the affected communities, ii) national health and water resources authorities, and iii) the international funding agencies who support arsenic reduction programs across low-income countries. An effective national arsenic eradication plan needs to address five aspects:

- $\quad$ Prioritise community buy-in for technology selection

- $\quad$ Consider alternative water sources

- $\quad$ Establish rigorous water quality monitoring

- $\quad$ Ensure that national and international partners contribute to the national system and priorities

- $\quad$ Evaluate and select the most appropriate arsenic removing technologies 
A significant reason why arsenic contamination of water continues to threaten populations after decades of programs and interventions is the lack of continuity in project planning and investment. Arsenic removal technologies need to be accepted by the communities that use them. A good-sense guiding principle for lowincome settings is that if an effective, locally developed and accepted arsenic removing technology exists, this is likely the best starting point to ensure long-term safe water in an arsenic-affected location. Many past solutions have been 'one shot' interventions by well-intentioned international organizations. But this often results in:

- A lack of engagement with the community to build trust and buy-in for a proposed removal technology;

- Inadequate long-term support for removal solutions that require components that are too expensive for community budgets, or not locally available.

\section{Consider alternative water sources}

Arsenic mitigation and eradication strategies are not limited to dealing with contaminated water. In certain cases, it is more effective to look beyond arsenic removal technologies to develop alternative water sources. Deep wells with filtering technologies can be a solution. They are often referred to in studies and technical reports as a stable source of clean water in arsenic-affected areas. But deep well groundwater is not guaranteed to be arsenic-free. In arsenic-prone areas, each deep well needs a case-by-case evaluation and continuing monitoring over time - ideally its own arsenic monitoring system. Other water sources can include transporting clean water to affected communities from another location, piped water infrastructure or rainwater harvesting in areas with sufficient rainfall.

\section{Establish rigorous water quality monitoring}

A rigorous spatially and timely distributed groundwater quality monitoring approach is a way to ensure coherent national level water quality governance, while keeping a finger on the pulse of monitoring in local communities across thousands of water sources. Families can use low-cost testing kits to check arsenic contamination at household and community level. These results can then be linked to a country-wide data collection system that gives public health authorities an overview of arsenic contamination at the national scale, and of the performance of all filtering technologies that are in place.

Ensure that national and international partners contribute to the national system and priorities

In the past decades, hundreds if not thousands of technical specialists and researchers have analyzed the arsenic-groundwater issue across the globe. International research teams have visited hundreds of villages to study the topic for their research projects. These investigations generate valuable insights that can help countries and communities overcome arsenic poisoning - but only if the data and findings are shared with communities and feed into a national arsenic reduction plan.

An effective national arsenic reduction plan includes a clear framework for how all international NGO and research partners will align with national priorities and agencies to share their data and engage in the technologies that are being offered. It sets rules that all projects and programs must follow. If external partners do not guarantee a longer-term presence for follow-up with users, or support for equipment maintenance, and if a technology is not integrated into the local context, it risks not being used, or seen as irrelevant by users.

Evaluate and select the most appropriate arsenic removal technologies

There is a wealth of studies on arsenic in groundwater and related arsenic removal approaches. (Kabir and Chowdhury, 2017). The recently published UNU-INWEH review (Shan et al, 2018) identified some 17,400 arsenicrelated publications between just 2014 and 2018. The review aimed to give a summary of the cost effectiveness and performance of a range of arsenic filtering technologies, and to suggest a standard on how such technologies should be reported for practical use and comparison with others. A total of 37 arsenic remediation technologies was compared; 23 were tested in laboratory settings and 14 in the field.

The laboratory tests used groundwater from Argentina, Bangladesh, Cambodia, China, Guatemala, India, Thailand, the United States, and Vietnam. They reveal filtering efficiencies ranging from $50 \%$ 100\%, with most technologies higher than $90 \%$. Some 50\% achieved the $\mathrm{WHO}$ standard of $10 \mathrm{\mu g} / \mathrm{L}$ of arsenic. Technologies were field-tested at household or community level in Argentina, Bangladesh, Chile, China, India, and Nicaragua.

They showed arsenic removal of 60\% 99\%, with 10 of the technologies removing more than $90 \%$ of contaminants. Only five met the WHO arsenic contamination standard.

There is currently a lack of attention by producers of existing arsenic remediation methods to their market viability. As a result, methods proven to be effective in the laboratory may remain trapped in the research phase and unable to continue to commercialization.

\section{Setting the standards right}

The WHO's provisional guideline for arsenic content in drinking water sets a level of $10 \mu \mathrm{g} / \mathrm{L}$ to protect populations against arsenic poisoning $(\mathrm{WHO}, 2011,2018)$. Some countries have set their national arsenic contamination standards less strict than WHO guideline, accepting higher arsenic concentrations, hence allowing them to report that they 'meet the national standard for arsenic contamination in groundwater'. While this creates positive reporting results, it is detrimental to efforts to eradicate arsenic poisoning and to public health in a country. 
Many methods need proofing in the field. Proven market viability is crucial to attract investment and develop efficient supply chains for new arsenic removal technologies, and to make them more accessible in remote regions.

Yet, the 'best technology' on the market is not necessarily best suited for a specific community, and, as mentioned earlier, there needs to be a mechanism that guarantees its long-term operation and maintenance. Also, some methods that are effective and low-cost may result in secondary contaminants and require additional treatment or disposal. Other effective and low-cost solutions require chemicals to synthesise the process, which may be impractical for locations that do not have easy access to these materials.

Some technologies that remove arsenic effectively at lower concentrations may be less effective for higher loads. Regular review of arsenic interventions should be built into national/local water management processes, where relevant authorities are ready to revise current arsenic removal technologies if they are less effective over time.

Most importantly, a complete shift in thinking on national water safety standards is necessary: arsenicremoval technology should be seen as 'efficient' only if it meets the WHO standard.

\section{Developing a national action plan for arsenic groundwater management}

The specific situation of each country affected by arsenic contamination of groundwater is unique. But there are many common issues and policy elements that decision makers and line agencies need to put in place in their national plan. The following draft framework presents elements of such a plan, encompassing issues of health, environment, water resources management, agriculture and rural development.
A regular community-based groundwater monitoring/recording system to identify the spatial distribution of arsenic in the country and its hot spots

Standards for acceptable arsenic contamination of groundwater as a policy
Connect with existing groundwater monitoring network or establish one if it does not yet exist. Involve local communities in monitoring/recording arsenic data

Mainstream groundwater quality standards into the national water policy

WHO standard $(10 \mu \mathrm{g} / \mathrm{L})$ should be used as the default and ultimate target/standard. National Standards that are less stringent than $\mathrm{WHO}$ arsenic contamination levels should be seen as unacceptable for long term public health planning. They could be an interim milestone to achieving WHO levels in the near future
An agency that monitors and regulates groundwater extraction/groundwater quality/quantity in the country

Health Ministry that sets and enforces standards free water, in actions such as: a nationally distributed water purification program; financial and medical support to the communities exposed to arsenic, capacity building at community level
National practices to achieve arsenic

Educate all stakeholders in national priorities and practices for arsenic removal

Prioritise locally developed arsenic removal technologies. Encourage their use if efficient, before looking to internationally-available solutions

Develop a family-level testing of water sources with low-costs kits

Evaluate and compare technologies for their efficiency and cost in local context

technologies in a low-income setting
Provide technical guidance/training to evaluate the cost and efficiency of removal technologies
Water, Health and Education Ministries

Local communities and NGOs
Set framework that defines national priorities that international partners and research teams will align with to share data from studies, propose technologies and engage with communities
Water/Health Ministries with NGOs
Guidelines for technology providers and international research groups to engage with communities

\section{A national process to assess the progress} of arsenic removal effort over time
Engage services by national/local authorities and academic/research institutions
Water/ Health Ministries, local communities and International Research Groups; NGOs
Water/Health Ministries, NGOs; Academic/Research Institutions; Local communities 


\section{References:}

Kabir, F. and Chowdhury, S. (2017). Arsenic removal methods for drinking water in the developing countries: technological developments and research needs. Environmental Science and Pollution Research, 24 (31), 24102-24120. DOI: 10.1007/s11356-017-0240-7

Ravenscroft, P., Brammer, H. and Richards, K. (2009) Arsenic Pollution: A Global Synthesis. (pp. 1-588), Wiley-Blackwell, Chichester, UK.

Shan, Y. Mehta, P., Perera, D., Varela, Y. (2018). Cost and Efficiency of Arsenic Removal from Groundwater: A Review. UNU-INWEH Report Series, Issue 05. United Nations University Institute for Water, Environment and Health, Hamilton, Canada.

WHO- World Health Organization (2011) Guidelines for drinking-water quality (4th ed.). Retrieved from http://apps.who.int/iris/bitstream/ handle/10665/44584/9789241548151_eng.pdf

WHO- World Health Organization (2018). Arsenic [Fact sheet no. 372]. Retrieved from http://www.who.int/mediacentre/factsheets/fs372/ en/

Authors: Duminda Perera, Michael Devlin and Vladimir Smakhtin

Suggested citation: Perera et al, 2019. Arsenic in groundwater: Elements of a National Strategy for Reduction and Eradication. UNU-INWEH Policy Brief, Issue 5. United Nations University Institute for Water, Environment and Health. Hamilton, Ontario, Canada.

Photo credit: Shutterstock.com

Layout and design: Kelsey Anderson

ISBN: 978-92-808-6097-9 